forestry departments in the world at the present day in which the demand for high-quality forest seed of many varying species does not exist, and, in the case of exotics, this often has to be imported. The objective of the study was to provide a "real average sample". At the beginning of the past decade, a new experimental selection method was introduced by Prof. Lars Tirén, director of the State Forest Research Institute's Forest Department, in the seed experiments of the Institute, which was described in 1948 in an essay published in the Institute's Proceedings (37, No. 5). Einar Huss's paper reviews the manner of treating cones and seed from Scots pine and Norway spruce. In eight short sections he deals with definitions and quantitative units, collection of cones, storage, selection, extraction of seed, de-winging and cleaning, sampling and germination. The ninth soction treats of storage and the mothods in use. The whole article merits close study by all foresters having to deal with this important seed problem.

\section{Pea Embryos in Sterile Culture}

As interesting contribution to our knowledge of the hormonization of seeds by growing dissected-out pea embryos in sterile culture has recently been made by W. Kruyt (Proc. Koninkl. Nederlandse Akad. van Wetensch., Ser. C., LV, 4, 503; 1952). The peas were sterilized externally and the embryos removed with or without the attached cotyledons and grown in a sterile culture medium. Various pre-soaking treatments, for example, with and without growthregulating substances, were investigated, and also the effects of factors in the culture medium and of leaving larger or smaller amounts of cotyledon attached to the growing embryo. It was found that the ratio of the amount of reserve material (in the cotyledons) to the size of the embryo bas an important effect on development, that is, nutrition affects the morphogenetic development, the growth of root and sprout being stronger in proportion to the amount of cotyledon tissue left on the embryo. No development of leaves takes place in the dark, and, even in the light, embryos from which the cotyledons have been removed scarcely form leaves : leaf development, in fact, is in proportion to the amount of cotyledon left on the embryo. The author also reports the liquefaction of agar gels, especially by embryos with attached cotyledons. The development of lateral roots is mainly dependent on the amount of cotyledon tissue present. In a considerable series of experiments the action of various growth substances was also examined, the conclusion being reached that the greater part of the action of a growth substance, administered by pre-soaking the seeds, takes place by way of the cotyledons.

Life Insurance Medical Research Fund of Australia and New Zealand

THE Life Offices' Association for Australasia has established the Life Insurance Medical Research Fund of Australia and New Zealand to promote and assist scientific and medical research. For the present it is intended to use the resources of the Fund to stimulate and support research in the field of cardiovascular function and disease, and for this purpose the Fund is offering grants-in-aid and research fellowships. Grants-in-aid will be given to non-profit institutions with basic facilities and qualified personnel for medical research and will be used in support of specific programmes of research, both fundamental and clinical, under the direction of a particular investigator; the grants will be worth $£ 1,000-3,000$ a year (or more, in exceptional circumstances) for one to three years and are designed to cover all the financial requirements of a programme, except the salary of the head of the department or institute concerned. Research fellowships will be awarded to medical graduates, or those with equivalent scientific training, for full-time research, and will be divided into three categories: fellowships taken up in Australia and New Zealand, of $£ 1,250$ 1,500 a year in value, which will be for one year (but renewable for further periods); travelling fellowships, of $£ 1,500-2,000$ a year in value plus travelling expenses, which will be for two years abroad, followed by a third year in an approved institution in Australia or New Zealand; and senior fellowships, which will be granted in special circumstances. Application forms (to be returned by March 31) and further information can be obtained from Dr. John H. Halliday, Medical Director, Life Insurance Medical Research Fund of Australia and New Zealand, 87 Pitt Street, Sydney, N.S.W.

\section{Book Service for Industrial Operatives}

THE National Book League is seeking information regarding the availability and use made of works libraries, with the view of the eventual establishment of a consultative service to factories, as visualized in a report of its Books in Industry Committee in 1949. Factory managements or their libraries are being invited to supply details regarding the size of the technical library they maintain from their budgets, the number of general books thus maintained, and whether or not $\mathbf{a}_{\text {w }}$ works librarian is employed and the library regularly brought up to date and at what cost. Information regarding facilities invited from public libraries includes the accessibility of books to operatives and the extent to which the books are used. The service contemplated is for the man at the bench rather than for scientific or research staffs. Information should be sent to Mr. R. Lusty, chairman of the Books in Industry Committee, National Book League, 7 Albemarle Street, London, W.l.

\section{British Agricultural History Society: Meeting in Reading}

A New Society, to be known as the British Agricultural History Society, has recently been formed, and it is hoped that, besides the academic backing which it already enjoys, it will receive the support of a wide circle, including both farmers and townsmen, for whom the history of British rural life is of real interest. The first general meeting of the Society will be held in the University of Reading during April 13, and all who are interested are welcome to attend. The conference will open at 10.30 a.m. with the adoption of the constitution of the Society, which has been drafted by the provisional committee elected at the inaugural meeting last September, and with the election of officers. Following this formal business, Sir James Scott Watson will read a paper on "The Scope of Agricultural History". In the afternoon, Sir Frark Stenton will read a paper on "The Manor in English History". Visits to the Museum of English Rural Life, Reading, will be arranged during the day. 'The registration fee for the conference is $3 s$., and should be sent to the secretary of the Society, Mr. J. W. Y. Higgs, Keoper of the Museum of English Rural Life, Shinfield Road, Reading, Berks, from whom all further information can be obtained. 